\title{
CLASSICAL THEORY OF INVESTMENT: PANEL COINTEGRATION EVIDENCE FROM 13 EU COUNTRIES
}

\author{
CONSTANTINOS ALEXIOU ${ }^{\star}, \dagger$, PERSEFONI TSALIKI ${ }^{\dagger}$ AND \\ LEFTERIS TSOULFIDIS ${ }^{\ddagger}$ \\ ${ }^{\star}$ Cranfield University; ${ }^{\dagger}$ Aristotle University of Thessaloniki and ${ }^{\ddagger}$ University \\ of Macedonia
}

\begin{abstract}
In the realm of macroeconomic theory, it is well established that investment decisions play an instrumental role in the determination of the level of output and employment; nevertheless, little progress has been made in relation to the theoretical aspects of these decisions. This paper, inspired by the classical approach to capital accumulation as well as the Keynesian theory of effective demand, attempts to enhance our empirical understanding of what determines investment decisions by exploring profitability, financial as well as demand factors. In so doing, a 'Fully Modified OLS' panel cointegration framework, for a cluster of two distinct groups of EU countries classified as core and the peripheral economies, provides the platform upon which our econometric investigation takes place. The respective evidence generated from the estimation process is in line with the theoretical framework proposed in this paper.
\end{abstract}

\section{INTRODUCTION}

The great recession of 2008 in conjunction with its concomitant implications, i.e. the slowdown in capital accumulation and the inexorable high levels of unemployment across many EU countries, has naturally given rise to a host of questions regarding the determinants of investment as well as the nature of the economic environment conducive to economic growth. Although investment is generally recognized as the key variable to promote economic growth and reduction of unemployment; nevertheless the precise nature of the investment decisions remains a puzzling and still largely unresolved question in economic theory and that little progress has been achieved. Of course, we know that the investment decisions are motivated by expected profits, but the precise modelling of a well-behaved investment function with profitability as the principal independent variable still remains an open question, inasmuch as in this function enter arguments such as uncertainty and expectations, which are very hard to quantify let alone adequately theorize. 
Given the above-outlined difficulties, this paper makes no claims to deal with the hard theoretical questions determining investment decisions and its purpose is restricted to the use of a much more modest theoretical framework within which empirical investigation may be carried out. More specifically, the objective of this paper is two fold in a sense that it attempts on the one hand to explore the conditioning factors of investment decisions, whilst it attempts on the other hand to shed some light on the relative importance of these factors in both the short and the long run. Our data set consists of $13 \mathrm{EU}$ countries, which for the purpose of our investigation is split into two clusters: the core economies (Belgium, Denmark, France, the Netherlands, Austria, Finland, Sweden, and the UK) and peripheral economies (Portugal, Italy, Ireland, Greece, and Spain), which share some commonality in economic environments and became historically known as PIIGS. Our endeavour is primarily focused on the extent to which there is a significant difference between the respective clusters of our sample in terms of the determination of investment. In passing, it should be stressed that the envisaged contribution of this paper is on the empirical treatment of the investment function at hand.

The remainder of the paper is organized as follows: Section II reviews the relevant literature and examines the rationale behind the specification of the empirical model. Section III introduces the variables that will be used in the econometric specification and pays particular attention to the profitability variable and the rationale for its use. Section IV sets out the econometric methodology adopted for the estimations. Section $\mathrm{V}$ presents and discusses the results of our econometric analysis. Finally, Section VI concludes by delineating some policy implications.

\section{REVIEW OF LITERATURE}

Investment activity is undoubtedly a source of economic growth, well-being, and economic stability. Over the years, various theoretical frameworks have been put forward in an attempt to effectively explain variations in investment activity. It is well documented that investment expenditure is one of the key components of aggregate demand that conditions, through the introduction and diffusion of new technology, economic activity and hence, employment.

Whilst the standard neoclassical theory emphasizes the importance of interest rate and prices, in general, in the determination of investment-saving decisions, the Keynesian and many heterodox economists, however, place particular emphasis on the accelerator type of models. On the one hand, they tend to downplay the role of prices and, in particular, the rate of interest whilst, on the other hand, elevate the demand gap as the principal determinant of investment decisions. The neoclassical idea is that the rate of interest implies an investment demand schedule and that the equality of savings and investment is attained through variations in the rate of interest and that full employment level of output can be established assuming that there is enough price flexibility. Furthermore, the investment demand schedule and the associated with it trade-off between investment and rate of interest leads to the 
measurement of capital whose consistency with the requirements of the neoclassical theory of value necessitates the hypothetical one-commodity-world economy. ${ }^{1}$ Eatwell and Millgate (2011) cast doubt on the alleged inverse relationship between investment demand schedule and interest rate on the following grounds ' $[\mathrm{i}] \mathrm{n}$ neoclassical theory, investment is reduced to an element within the theory of value and distribution, the function relating investment to the rate of interest being confronted with a function relating saving to the rate of interest in order to determine the equilibrium volume of saving and investment. As the capital theory debates have shown, this view of investment is logically untenable' (p. 168). Investment decisions in this perspective cannot be fully theorized, yet we can make some general remarks and select important variables such as demand growth - which is central in regulating investment decisions - but in no way these variables will they become part of a general theory of uncertainty-ridden investment decisions. This however by no means does it indicate that profitability and the interest rate are not linked to the investment decisions. On the contrary, investment decisions are governed by profitability and interest rate, but the inherent linkage should be assessed and understood within the process of capital accumulation (see also Eatwell and Millgate 2011, pp. 168 and 228).

Despite the theoretical lacuna with respect to uncertainty characterizing the investment decisions, the old classical economists and Marx thought that the difference between the rate of profit and the rate of interest (i.e. the net rate of profit or 'the rate of profit of enterprise' according to Marx) is a crucial determinant of investment. The same is true with Keynes (1936) whose investment decisions, i.e. 'the supply price of capital' depends on the difference between the marginal efficiency of capital (MEC), that is, Keynes's definition of profitability, and its difference from the rate of interest, the so-called 'profitability gap', which is expected to stimulate investment expenditures (Richardson and Romilly, 2008). It is important to point out that Keynes (1936, p. 140), in his effort to find precursors to his ideas, wrote that his concept of MEC was 'identical' to Irving Fisher's definition of the 'rate of return over cost'. Upon careful examination, however, we discover that the profits in Keynes's conceptualization are expected, unobservable and therefore not realized, and in this sense his concept of the MEC, derived 'last of all, after an immense lot of muddling and many drafts' (Collected Writings, xiv, p. 85), is consistent with his theory effective demand. ${ }^{2}$ Keynes (1936, p. 213) also explicitly rejected the idea of marginal productivity of capital as the determinant of the value of capital (Tsoulfidis, 2008). ${ }^{3}$ In similar fashion, Kalecki (1968, pp. 96-99) emphasizes the net rate of profit as the key variable in the investment function and by doing so shares the view of profit-driven

\footnotetext{
${ }^{1}$ For the discussion of the famous capital theory controversies, we recommend the readings conveniently collected in Eatwell et al. (1993).

2 Profitability as a determinant of investment has been pointed out by a number of authors that would subscribe to the modern classical approach (Vianello, 1985; Ciccone, 1986, Kurz, 1990; inter alia).

${ }^{3}$ Garegnani (1978-1979) also rejects the idea that Keynes's MEC is the same as in Fisher's 'rate of return over cost' on the grounds that the MEC does assume neither full employment of labour nor the marginal productivity theory of income distribution.
} 
capital accumulation (see also Sawyer, 1985, p. 95). It is worth stressing at this point that the effect of profits is distinct from the effect of demand (capacity utilization) on investment.

In most of the earlier studies, investment expenditure is taken as the dependent variable either in absolute terms and measured in constant prices or as a percentage of the capital stock (i.e. the rate of capital accumulation). Junankar (1972) in his important study derived that the accelerator is a by far more important influence on investment than the rate of interest. This view is consistent with the ideas of Keynesian and post-Keynesian economists of the 1960s and 1970s, who downplayed the view that investment decisions of firms are regulated by the (real) rate of interest (assumed to be equal to the rate of profit) and that the level of demand is by far the most crucial variable in shaping these decisions. In this respect, it is interesting to note that Junankar (1972), who is apparently influenced by the capital controversies of the 1960s, is blatantly clear on issues relating to the measurement of aggregate capital stock in a way, which is consistent with the tenets of the neoclassical theory. More specifically, he contends that problems relating to capital measurements can be surmounted by measuring capital in terms of actual markets prices. In the following years, a number of studies, utilizing time series econometric methodologies, provided evidence that prices may have a significant effect on investment decisions (see for instance Bean, 1981 and Catinat et al., 1987). In reviewing the past empirical studies of investment behaviour, Chirinko (1993) reached the following general conclusion according to which, neither the profit rate nor the interest rate (i.e. the price variables) prove to be statistically important in the investment decisions. He notes that 'the response of investment to price variables tends to be small and unimportant relative to quantity variables' (Chirinko, 1993, p. 1906).

\section{PRICE VARIABLES AND THE INVESTMENT FLOWS}

Although the past econometric literature de-emphasized the importance of the socalled price variables, this may be explained partly by the lack of reliable and longrun time series data; partly by the econometric techniques, which suffered from a number of problems that now we can cope with using panel unit root tests and panel cointegration; finally, the econometric specification usually was not the most appropriate to capture the effects of price variables. In our econometric specification, we take the growth rate of investment as the appropriate index, which essentially indicates the acceleration or deceleration of capital accumulation. As independent variables, we include the incremental rate of profit (IROP) as an index of profitability, the real prime interest rate as an index of financial conditions, and the growth rate of real gross domestic product (RGDP) as our proxy for the demand conditions or acceleration effects and we also use lags of the dependent variable to capture the possible cumulative and diffusion of technology effects of past investment activity. The major advantage of such econometric specification is that in our measure of profitability, we dispense altogether with the capital stock and the difficulties, theoretical 
and empirical, associated with its measurement as produced (means of production) goods. As a consequence, the gross investment expenditures, used in our profitability variable (see below), have the advantage that their measurement is straightforward and common across countries and also over the years.

The profitability conditions are captured by the IROP, that is, the change in real gross profits over the real gross investment of the last period. The idea is that the economywide average rate of profit commonly used in investment or capital accumulation econometric specifications is a weighted average of all firms operating in all industries and it is not necessarily the rate of profit that actually becomes the magnet or repeller of the bulk of investment activity. Thus, the decisions to invest are motivated by the profitability of the leading firms (called 'regulating capitals') activated in each industry.

The underlying principles of the IROP are described in Shaikh (1997) according to which investment is attracted more by the recent returns on investment rather than on returns on all past investments. Thus, starting from the current period flow of profits $\left(\Pi_{t}\right)$ derived from two sources: first from the profits on most recent investment $\left(I_{t-1}\right)$ multiplied by a markup $(\rho)$ to be determined and second from the profits that accumulate to a firm from all other past investments $\left(\Pi^{*}\right)$. Thus, we may write:

$$
\Pi_{t}=\rho I_{t-1}+\Pi^{*}
$$

If we subtract profits of the previous period from both sides of the above equation, we get:

$$
\Pi_{t}-\Pi_{t-1}=\rho I_{t-1}+\left(\Pi^{*}-\Pi_{t-1}\right) \quad \text { or } \quad \Delta \Pi_{t}=\rho I_{t-1}+\left(\Pi^{*}-\Pi_{t-1}\right)
$$

The term in parenthesis in the above equation is expected to be small, much smaller when compared to the term $\rho I_{t-1}$, which is another way to say that its total effect

is negligible and for all practical purposes the profits of all past periods may be safely ignored (Shaikh, 1997; Elton et al., 2003, ch. 18, p. 448). Vaona (2011) and Bahçe and Eres (2012) also argue that the term in the parenthesis is not only relatively small, but also mean (zero) reverting. Moreover, current profits are loaded with so many ephemeral elements, and we do know that abnormally high (or low) profits attract (or repel) investment flows. Thus, it is reasonable to assume that expectations about future returns to investment are not far sighted and so the current rate of return on new investment will be:

$$
\rho \approx \frac{\Delta \Pi_{t}}{I_{t-1}}
$$

that is, the ratio of the current change in gross real profits to gross real investment lagged by one period. This ratio is called the IROP and it provides us with a practical 
guide to identify indirectly the profitability on the leading firms (or the regulating capitals) of an economy over the years. The IROP refers to short-run profitability, i.e. profits derived from the most recent investment, which are those that form the short-run investors behaviour. Thus, the IROP becomes the short run or more immediate regulator of the investment activities, whereas lurking underneath the IROP is the average rate of profit derived from profits of all (recent and past) investment. The average rate of profit becomes the long-run regulator of investment flows providing both the funds and also shaping more or less the general psychology (optimism or pessimism) of the business community. In effect, profits influence investment not only by providing the motivation to invest but also the means (Robinson, 1962, p. 86).

This does not mean that the two rates of profit are totally distinct from one another. On the contrary, it just means that the average rate of profit, $r$, being the average of all firms in the economy does not really capture the ebbs and flows of investment activity. In effect, the average rate of profit, $r$, and the IROP are strictly related to one another and this relation can be seen starting from the definition of profits $\Pi=r \cdot K$, whose total differential in discrete time will be

$$
\Delta \Pi \approx r \Delta K+K \Delta r
$$

By dividing by $\Delta K \neq 0$, we get:

$$
\frac{\Delta \Pi}{\Delta K} \approx r+\frac{\Delta r}{\Delta K} K
$$

or

$$
\rho \approx r\left(1+\frac{\Delta r}{\Delta K} \frac{K}{r}\right)
$$

where the term in the parentheses is a kind of a markup that makes the IROP a variable characterized by turbulent dynamic behaviour, a feature that is a reflection of the short-term nature of excess profits (or losses), which really act as attractors (or repellers) of inflows of new investment expenditures between countries. Clearly, the term $(\Delta r / \Delta K)(K / r)$ is what makes the IROP to gravitate around the economy-wide average (or normal) rate of profit, $r$. The latter more or less determines the general outlook of the business community toward investment expenditures. The IROP wandering around the economy-wide average rate of profit determines the acceleration or deceleration of capital accumulation.

Not surprisingly, the notion of IROP is also connected to the MEC, a short run Keynesian index of profitability (Tsoulfidis and Tsaliki, 2012). We start from the well-known formula of the internal rate of return, 


$$
I_{t-1}=\Pi_{t} \cdot(1+d)^{-1}+\Pi_{t+1} \cdot(1+d)^{-2}+\cdots
$$

where $d$ is the interest rate or the internal rate of return on investment. Differentiation of investment with respect to $d$ gives:

$$
\frac{\mathrm{d} I_{t-1}}{\mathrm{~d} d}=-\Pi_{t} \cdot(1+d)^{-2}-2 \Pi_{t+1} \cdot(1+d)^{-3}-\cdots
$$

Assuming equality of profits in all periods, it follows that the longer the time horizon, the more negative the associated with these periods profits. Thus, having to choose between short-term and long-term projects, entrepreneurs opt for the former rather than the latter, and in particular $d=\Pi_{t} \cdot\left(I_{t-1}\right)^{-1}-1$ (Scherer and Ross, 1990; Tsoulfidis and Tsaliki, 2012). Since investment and profits are strictly related to each other, it follows that both $\rho$ and $d$ are neither too far, nor unrelated to each other.

The financial conditions, so important for both the upturn as well as the current Great Recession, are reflected in the movement of the prime real interest rate (RIR). This suggests that an increase in interest rates dampens planned investment expenditures, reduces productive capacity growth and potential output, and undercuts the need for labour to produce the lower output, thereby increasing the unemployment rate. It should be stressed that neither the IROP nor the RIR should be thought of as the key factors responsible for equilibrating saving and investment. The IROP and the RIR should be seen in a broader classical perspective according to which the rate of interest is a derived (from the total profits or surplus value produced) variable, which in relation to the relevant rate of profit govern the process of capital accumulation. The two variables together form what may be called 'profitability gap', which shapes the investment decisions and it is a common theme, which characterizes many of the major economists of the past. For example, in Marx (1894, p. 368) we have the profit rate of enterprise, in Keynes (1936, pp. 135-146) the MEC, in Kalecki (1968) clearly the difference between profit and interest rates is decisive in the investment decisions of firms (Richardson and Romilly, 2008). It is worth stressing that this characteristic feature is not specific to classical approach but rather is shared (with important conceptual differences) by all contending approaches (Mejorado and Roman, 2014, p. 191).

Finally, the growth in demand elicits changes in investment expenditures. This is the accelerator principle that Keynesian economists, by and large, give a lot of weight to and in the first empirical studies of investment behaviour, this was the variable that turned out to be perhaps the single most important.

With the passage of time, data are more easily accessible but moreover extend to a much longer period of time and are selected in a more or less uniform way for a number of countries. Meanwhile, the econometric techniques that have been developed allow tests with more definitive results. Thus the combination of longer time series and more homogenous data sets across countries together with more advanced econometric techniques has, from a practical point of view alone, changed 
fundamentally the way that we look at variables and the way that investment decisions are shaped.

\section{MODEL SPECIFICATION}

This section considers the empirical determinants of investment. The empirical specification of the investment regressions is a variant of the standard investment specifications encountered in the literature (see for instance Keynes (1936), Kalecki (1968), Sawyer (1985), Alexiou (2010) and Tsoulfidis and Tsaliki (2014)).

The data set used (subject to availability) spans over the period 1980-2013, consisting of $N$ cross-sectional units, denoted $i=1, \ldots, N$ observed at $T$ time periods, denoted $t=1, \ldots, T$. More specifically, $y$ is a $(T N \times 1)$ vector of endogenous variables, $x$ is a $(T N \times k)$ matrix of exogenous variables, which does not include a column of units for the constant term. In this context, we collated data for the two country clusters, namely, the core cluster (comprising eight countries: Belgium, Denmark, France, the Netherlands, Austria, Finland, Sweden, and the UK) and the peripheral cluster (comprising five countries: Ireland, Greece, Spain, Italy, and Portugal). ${ }^{4}$ The main data provider was AMECO database.

The generic linear econometric form of the model utilized can be expressed as follows:

$$
\begin{gathered}
y_{i t}=\alpha_{i}+\beta_{i} X_{i t}+\varepsilon_{i t}, \\
\varepsilon_{i t} \sim \text { i.i.d. }\left(0, \sigma_{i}^{2}\right) .
\end{gathered}
$$

where $y_{i t}$ is the dependent variable, $\alpha_{i}$ is the intercept term through, which we may include factors such as innovations, technological progress, and 'animal spirits', $\beta_{i}$ is a $k \times 1$ vector of parameters to be estimated on the explanatory variables, and $X_{i t}$ is a $1 \times k$ vector of observations on the explanatory variables, $t=1, \ldots, T, i=1, \ldots, N$, and $\varepsilon_{i t}$ is a random term, assumed to satisfy the normal requirements.

In this context, we estimate various specifications of model (1), the explicit form of which is expressed as follows:

$$
\begin{aligned}
\mathrm{RINV}_{i t} & =a_{0}+a_{1} \mathrm{IROP}_{i t}+a_{2} \mathrm{RGDP}_{i t}+a_{3} \mathrm{RIR}_{i t}+\varepsilon_{i t} \\
\varepsilon_{i t} & =v_{i}+u_{i t}
\end{aligned}
$$

where RINV is real gross capital formation, IROP stands for the incremental rate of profit, which is defined as the change in current real net profits over real net

\footnotetext{
${ }^{4}$ It should be stressed that we have deliberately left out Germany due to inconsistencies associated with data collection prior to German unification in 1990 .
} 
investment, ${ }^{5}$ RGDP is real gross domestic product, RIR denotes real interest rates, $\varepsilon_{t}$ is the disturbance term, $v_{i}$ captures the unobserved country-specific effect while $u_{i t}$ is the idiosyncratic error. This is a one-way error component regression model, where $v_{i} \sim \operatorname{IIN}\left(0, \sigma^{2}\right)$ and independent of $u_{i t} \sim \operatorname{IIN}\left(0, \sigma^{2}\right)$.

\section{4.a. Methodology}

Cointegration analysis provides the platform upon which our methodological endeavour unfolds.

IV.a.a. Panel unit roots. DF (Dickey Fuller) or ADF (Augmented Dickey Fuller) tests have been traditionally used to test for the presence of unit roots in univariate time series. The aforementioned tests, however, have been proven to suffer from low power in rejecting the null hypothesis of a non-stationary series as well as limiting distributions, which are complicated and not well defined. In recent years, further unit root tests have been developed-such as those by Levin et al. (2002), Im et al. (2003), and Hadri (2000) — which are shown to be more powerful than the unit root tests applied to individual series. While these tests are commonly termed 'panel unit root' tests, theoretically speaking, they are simply multiple-series unit root tests that have been applied to panel data structures (where the presence of cross sections generates 'multiple series' out of a single series). In this paper, we utilized both common root tests-Levin, Lin, Chu (LLC)—and individual root tests-Im, Pesaran, Shin (IPS), Fisher-ADF, Fisher-PP, and Hadri. Common root indicates that the tests are estimated assuming a common AR structure for all of the series; 'Individual root' is used for tests, which allow for different AR coefficients in each series.

\section{4.b. Cointegration}

Cointegration methodology is primarily used to investigate whether spurious estimation results are evident in the event of non-stationary time series. If such a stationary linear combination exists, the non-stationary time series are said to be 'cointegrated'. The stationary linear combination is called the 'cointegrating equation' and may be interpreted as a long-run equilibrium relationship among the variables. In other words, if two variables are integrated of the same order and these appear to be converging in the long run, then their extant relationship will produce errors, which are stationary. In order to determine whether such a long-run relationship exists, panel cointegration techniques advanced by Pedroni (1999) are utilized. Pedroni essentially builds on the two-step residual-based strategy of Engle and Granger (1987) to develop his own tests. On the basis of this approach, seven different statistics that test for

\footnotetext{
${ }^{5}$ As indexes of profitability, we also tried the average rate of profit and the Keynesian MEC data that are available in the AMECO database, however, both variables did not give better results compared to the IROP.
} 
panel cointegration are generated. Four are based on a within-dimension and three on the between-dimension. It is in this sense that the within-dimension-based statistics are referred to as panel cointegration statistics, whilst the between-dimension-based statistics are termed as group mean cointegration statistics. These tests are based on the null of no cointegration and work with the assumption of heterogeneous panels. The proper formulation for all seven tests is expressed as follows:

$$
y_{i t}=\alpha_{i}+\beta_{1} X_{1, i, t}+\beta_{2} X_{2, i, t}+\cdots+\beta_{n} X_{n, i, t}+\mu_{i t}
$$

where $X_{i, t}$ are the regressors for $n$ cross sections. A regression is then performed on the residuals resulting from equation (3):

$$
\mu_{i, t}=\zeta_{i} \mu_{i, t-1}+z_{i, t}
$$

The preceding estimation process generates seven different statistics, namely, the panel- $v$, panel- $\rho$, panel non-parametric- $t$, panel parametric- $t$ (the within-dimension), group- $\rho$, group non-parametric- $t$, and group parametric- $t$ (the between-dimension of the panel). In the within-dimension framework, the null of no cointegration and the alternative of cointegration are tested as follows:

$$
\begin{gathered}
H_{0}: \zeta_{i}=1 \text { for all } i, \\
H_{1}: \zeta_{i}=\zeta<1 \text { for all } i .
\end{gathered}
$$

This stands at stark contrast to the between-dimension framework where the alternative hypothesis states that $H_{1}: \zeta_{i}<1$ for at least one $i$. A rejection of the null hypothesis should therefore be taken as evidence in favour of cointegration for all individuals.

Note that, the between-dimension test is less restrictive and allows for heterogeneity across members. In the case of the within-dimension test, a common value for all cross sections is imposed, i.e. $\zeta_{i}=\zeta$. As the purpose of this paper is far from getting bogged down into technicalities, details of the intricate technical aspects of the respective unit root and cointegration tests can be sought in the original papers (see for instance, Pedroni 1999). What follows is the presentation of the Fully Modified Ordinary Least Squares (FMOLS) procedure, which serves as the platform upon which the panel cointegration estimation will unfold.

\section{4.c. Panel FMOLS}

Once cointegration has been established, we then proceed to estimating the model using the FMOLS techniques for heterogeneous cointegrated panels proposed by 
Pedroni (1996, 2000). According to Pedroni (2000), standard OLS estimation of a panel will produce an asymptotically biased estimator. He argues that only in the case of exogeneity of the regressors and homogenous dynamics across the individual members of the panel, is it possible for the OLS estimator to be unbiased.

The FMOLS estimates are superior to OLS estimates in a sense that they are able to account for both serial correlation and potential endogeneity problems. In addition, FMOLS methodology allows for the country-specific fixed effects to be heterogeneous while estimating long-run relationships. Pedroni (2000) also contends that $t$-statistics for group mean panel FMOLS offers more flexible alternative hypothesis than pooled panel FMOLS because the former are based on the between-dimension as opposed to within-dimension of the panel; thus it estimates the cointegrating vectors for a common value under the null hypothesis, while under the alternate hypothesis the values for the cointegrating vectors are allowed to vary across groups. The latter is of great significance in the context of Pesaran and Smith's (1995) finding that under heterogeneous cointegrating vectors across different countries, group mean estimators give consistent estimates of the sample mean of cointegrating vectors while pooled within-dimension estimators fail to do so.

In view of the above, the resulting FMOLS model assumes the following form:

$$
\begin{aligned}
& y_{i, t}=\alpha_{i}+\beta x_{i, t}+\mu_{i, t} \\
& x_{i, t}=x_{i, t-1}+\xi_{i, t}
\end{aligned}
$$

where $\alpha_{i}$ allows for the country-specific fixed effects, $\beta$ is a cointegrating vector given that $y_{i, t}$ is $I(0)$. The vector error process $\varepsilon_{i, t}=\left(\mu_{i, t}, \xi_{i, t}\right)$ is therefore a stationary process too. Note that Pedroni (2000) shows that the group mean FMOLS estimator is consistent and that the test statistic performs reasonably well even in small samples as long as the time period under consideration is not smaller than the number of cross sections.

The final step in the empirical procedure is the estimation of a panel error correction model (ECM) that will provide the short-run as well as long-run dynamics between the variables in the system.

\section{ESTIMATIONS RESULTS}

The analysis commences with an assessment of the integration properties of the variables incorporated in the model. As we indicated earlier, three different data sets are considered. One set of estimations deals with the presence of unit roots and cointegration in the entire data set, one assesses the existence of unit roots and cointegration in the core economies, whilst the third one deals with the data set consisting of the peripheral economies. Table 1 reports the panel unit roots test estimates for the respective data sets. 
TABLE 1

Panel Unit Roots Test

\begin{tabular}{|c|c|c|c|c|c|c|c|c|c|c|}
\hline & \multicolumn{5}{|l|}{ Levels } & \multicolumn{5}{|c|}{ First difference } \\
\hline & LLC & IPS & ADF-F & PP-F & Hadri & LLC & IPS & ADF-P & PP-F & Hadri \\
\hline \multicolumn{11}{|c|}{ Core economies } \\
\hline RINV & 0.87 & 2.84 & 2.61 & 3.1 & $8.71^{\star}$ & $-6.06^{\star}$ & $-7.96^{\star}$ & $90.4^{\star}$ & $41.2^{\star}$ & -1.23 \\
\hline IROP & $-8.55^{\star}$ & -5.38 & $57.1^{\star}$ & $54.6^{\star}$ & $6.56^{\star}$ & $-14.6^{\star}$ & $-14.5^{\star}$ & $82.6^{\star}$ & $97.5^{\star}$ & 2.14 \\
\hline RGDP & -2.35 & $-4.26^{\star}$ & $35.6^{\star}$ & 27.9 & $3.70^{\star}$ & $-5.50^{\star}$ & $-5.61^{\star}$ & $60.1^{\star}$ & $65.1^{\star}$ & 1.98 \\
\hline RIR & -2.82 & -2.10 & 25.9 & 26.1 & 11.8 & $-14.8^{\star}$ & $-11.8^{\star}$ & $80.5^{\star}$ & $97.9^{\star}$ & 1.67 \\
\hline \multicolumn{11}{|c|}{ Peripheral economies } \\
\hline RINV & -1.91 & -1.04 & 11.7 & 5.26 & $4.37^{\star}$ & $-4.20^{\star}$ & $-4.35^{\star}$ & $37.2^{\star}$ & $24.1^{\star}$ & -0.17 \\
\hline IROP & $-4.48^{\star}$ & -3.65 & 6.73 & $26.5^{\star}$ & $5.79^{\star}$ & $-16.1^{\star}$ & $-18.2^{\star}$ & $40.1^{\star}$ & $92.1^{\star}$ & 0.49 \\
\hline RGDP & 0.54 & 0.65 & 4.48 & 3.48 & $4.53^{\star}$ & $-2.98^{\star}$ & $-3.36^{\star}$ & $27.8^{\star}$ & $27.9^{\star}$ & $3.26^{\star}$ \\
\hline RIR & -0.97 & -1.34 & 13.3 & 13.4 & $1.71^{\star}$ & $-13.8^{\star}$ & $-11.8^{\star}$ & $85.1^{\star}$ & $87.2^{\star}$ & -0.49 \\
\hline
\end{tabular}

Notes: $\left(^{\star}\right)$ denotes significance at the $5 \%$ level of significance. The models have been specified with individual effects. The null hypothesis for LLC, IPS, ADF-F, and PP-F is that of a unit root whilst the respective null hypothesis for Hadri's test is that of stationarity-Hadri's $z$-statistics are reported. 
An inspection of Table 1 suggests that all variables when used in levels form appear to be non-stationary. A closer look however suggests that a number of these tests regarding the variables IROP, RIR, and RGDP have turned out to be rather inconclusive. Evidently, when the first differences are taken, all variables are found to be integrated of order 1, i.e. $I(1)$. It should be noted that the tests were also performed with individual effects and individual linear trends-not reported in Table 1 due to economy of space-but no significant differences were observed.

\section{5.a. Cointegration analysis}

Even though it is well documented in the existing literature that it is not possible for two series integrated of different orders to form a cointegrated series, it is less acknowledged that it is possible that the combination of more than two series, which are integrated of different orders can form a cointegrated series of lower order of integration. In other words, if $x_{t} \sim I(1)$ and $y_{t} \sim I(0)$, then $x_{t}$ and $y_{t}$ cannot be cointegrated. However, if $x_{t} \sim I(2), z_{t} \sim I(2)$, and $y_{t} \sim I(1)$, then $x_{t}$ and $z_{t}$ can cointegrate to form an $I(1)$ series, which can then cointegrate with $y_{t}$ to give a $I(0)$ series (see Pagan and Wickens, 1989). Harris (1995) indicates that there can be up to $n-1$ linearly independent cointegrating vectors, where $n$ is the number of variables. In view of the latter, even if some of our tests for the order of integration are inconclusive, it is still possible to come up with multiple cointegrating vectors, which can then form a linear combination to generate an $I(0)$ series. Table 2 reports the panel cointegration estimates for all samples.

All the reported statistics in Table 2 suggest that there is evidence of a strong cointegrating relationship among the variables, when the dependent variable is investment. We also performed Kao's Residual Cointegration test and found a strong

TABLE 2

Pedroni's Cointegration Test Results

\begin{tabular}{lll}
\hline & Core economies & Peripheral economies \\
\hline Panel statistics (within-dimension) & & \\
$v$-statistics & -0.14 & -0.48 \\
$\rho$-statistics & $-5.25^{\star}$ & $-2.36^{\star \star}$ \\
pp-statistics & $-7.15^{\star}$ & $-5.67^{\star}$ \\
ADF-statistics & $-1.82^{\star \star}$ & $1.93^{\star \star}$ \\
Group statistics (between-dimension) & \\
$\rho$-statistics & $-4.54^{\star}$ & $-3.87^{\star \star}$ \\
pp-statistics & $-8.05^{\star}$ & $-7.67^{\star}$ \\
ADF-statistics & $-1.36^{\star \star \star}$ & $2.98^{\star \star}$ \\
\hline
\end{tabular}

Note: Pedroni (2004) residual cointegration tests. The null hypothesis is no cointegration. The models have been specified with deterministic intercept and trend. $\left({ }^{\star}\right),\left({ }^{\star \star}\right)$ and $(\star \star \star)$ denote rejection of the null hypothesis of no cointegration at $1 \%, 5 \%$, and $10 \%$ levels, respectively. 
cointegrating relationship across all data sets. More specifically, Kao's test rejected the null of no cointegration at the $1 \%$ level of significance.

\section{5.b. FMOLS estimation results}

Having established the existence of a cointegrating relationship, we then proceed to estimating the long-run parameters of our equation. Table 3 reports the estimates generated using the FMOLS estimator for all three respective samples.

A quick inspection of Table 3 reveals that in all samples the coefficients of the underlying variables bear the expected signs. In particular, the long-run cointegration results suggest that RIRs as well as demand growth exert a significant effect on investment, whilst IROP is highly significant in the case of the core economies and marginally insignificant in the case of the peripheral cluster of economies (Table 4). Further in to the analysis, we can also establish that demand-side management policies are thought to positively affect investment, and therefore enhance the economic environment where employment creation can be nurtured across the region.

The short-run evidence derived from the ECM is consistent with the expected theoretical framework thus, indicating a speedy convergence as this is reflected by the EC coefficient. In achieving convergence, IROP is statistically significant in both sets of economies lending support to the view that the IROP is potentially bound up with the short-term investment decisions. In the long run, however, the results suggest that investment decisions are more prone to be affected by the overall state of the economy as this is reflected by the growth of demand and the rate of interest. The latter ever since the 1980s has served as means of conducting monetary policies and is also considered to be responsible for restoring profitability in the 1980s up until the onset of the great recession in 2007 (see also Shaikh, 2016, ch. 16).

Given the dynamic process through which the error correction ensures that equilibrium is attained, it is worth emphasizing that such an attainment instead of eliminating any of the existing disparities, it rather drives a wedge between the EU core and peripheral countries. By and large, our results suggest the both the IROP and RIR are potentially instrumental in the determination of investment. We should not forget

TABLE 3

FMOLS Estimates

Long-run estimates: dependent variable is investment

\begin{tabular}{lcc}
\hline & Core economies & Peripheral economies \\
\hline IROP & $0.92(15.56)^{\star}$ & $0.61(1.66)$ \\
RGDP & $0.14(4.53)^{\star}$ & $0.20(6.14)^{\star}$ \\
RIR & $-4.07(-20.67)^{\star}$ & $-0.64(-3.02)^{\star}$ \\
\hline
\end{tabular}

Note: The models include common time dummies. $\left(^{\star}\right),\left({ }^{\star \star}\right)$ and $\left({ }^{\star \star \star}\right)$ denote significance at $1 \%, 5 \%$, and $10 \%$ significance levels, respectively. $t$-statistics are given in parenthesis. 
TABLE 4

Error Correction Estimates

\begin{tabular}{lcc}
\hline & Core economies & Peripheral economies \\
\hline$c$ & $-0.19(-0.64)$ & $0.01(0.10)$ \\
$\Delta \mathrm{RINV}_{t-1}$ & $0.52(5.49)^{\star}$ & $0.68(8.38)^{\star}$ \\
$\Delta \mathrm{RINV}_{t-2}$ & $0.04(0.45)$ & $0.15(1.96)^{\star \star}$ \\
$\Delta \mathrm{IROP}_{t-1}$ & $1.16(1.86)^{\star \star \star}$ & $0.19(2.21)^{\star \star}$ \\
$\Delta \mathrm{IROP}_{t-2}$ & $-0.49(-1.01)$ & $-0.10(-1.55)$ \\
$\Delta \mathrm{RGDP}_{t-1}$ & $1.46(4.43)^{\star}$ & $0.98(5.71)^{\star}$ \\
$\Delta \mathrm{RGDP}_{t-2}$ & $-1.42(-1.75)$ & $-0.95(-6.21)^{\star}$ \\
$\Delta \mathrm{RIR}_{t-1}$ & $-1.17(-3.12)^{\star}$ & $-0.84(-9.35)^{\star}$ \\
$\Delta \mathrm{RIR}_{t-2}$ & $-0.25(-1.06)$ & $-0.03(-0.47)$ \\
$\mathrm{EC}_{t-1}$ & $-0.25(-5.59)^{\star}$ & $-0.13(-4.05)^{\star}$ \\
\hline
\end{tabular}

Note: The values in parentheses denote the $t$-statistics. $\left({ }^{\star}\right),\left({ }^{\star \star}\right)$ and $\left({ }^{\star \star \star}\right)$ indicate statistical significance at $1 \%, 5 \%$ and $10 \%$ levels, respectively.

however that the implication of this evidence is far from straightforward either in the short or the long run as investment decision-making is inherently a complex process that is closely associated with the nature of the immediate economic environment. According to Kydland and Prescott (1977) and Davidson (1995), whenever economic environment changes, people' expectations follow suit. Given the interdependence of the global economic environment, it is therefore envisaged that investment-type modelling should move beyond the historically significant theoretical formulations, thus taking into account the uncertainty that permeates the global economy per se.

Further insights into the determination of investment could be potentially explored in future research on the distributional effects of finance on capitalist and industrial profits. Kalecki's (1968) approach to entrepreneurial capital might offer a channel through which the Minskian financial instability hypothesis is explained. The significance in Kalecki's theoretical argument is that a firm's access to the capital market is determined, inter alia by the amount of its entrepreneurial capital, i.e. the amount of savings out of financial profits that industrial firms hope to obtain is determined by the amount of industrial profits. It is in this sense that the expected total capitalist profits depend on effective demand and savings decisions of industrial and financial capitalists as well as on income distribution between capitalists and workers.

\section{CONCLUDING REMARKS}

Our empirical endeavour has generated evidence consistent with our theoretical exposition in terms of the signs and the statistical significance of the coefficients. All variables turned out to be statistically significant for the core economies apart from the peripheral ones, where the long-run estimate of IROP was only marginally insignificant. The implication of the latter might be that the existing austerity policies 
implemented in the distressed peripheral economies do not have the expected longrun stimulating impact on investment activity. In particular, the outright wage reductions in conjunction with an indiscriminate hike in income tax might have temporarily stifled economic activity. Such a notion is in line with the 'Kaldorian paradox' introduced by Nicholas Kaldor in 1966, on the basis of which higher labour share will not necessarily lead to a less competitive economy. To suggest therefore that lower unit labour costs will rejuvenate economic growth might be a highly simplistic view. It is in this sense that recently, an argument, that appears to be shared by a significant number of both academics as well as policy makers, states that increasing wages, i.e. dwindling profitability, in the core economies might be the right policy to reduce existing disparities across EU countries.

In the case of demand growth, the results are more straightforward, thus, suggesting that in both clusters of our countries demand-expansion policies may exert a significant effect on investment across countries. A result that is in line with the early studies of investment decisions where the role of accelerator was important.

The real rate of interest is in all cases statistically significant but its coefficient is by far larger in the core economies than in the peripheral ones. Thus, we may say that the policies of ECB of targeting interest rates benefit, in terms of attracting investment activity, more the core than the peripheral EU countries. It can also be deducted that the generated evidence suggests that continuation of the austerity programmes in the long run is likely to worsen the existing disparities amongst core and peripheral countries of the EU.

Future research may extent the scope of this analysis by introducing more variables into the econometric specification, such as, for example, risk (one measure might be the difference between the prime interest rate and EURIBOR), flows of lending funds from the financial system or more sophisticated variables capturing demand growth effects, such as, for example, the growth of capacity utilization (see Semmler and Franke, 1995). Finally, for profitability one could also use as a possible variable the Tobin-Q. Such experimentation, however, would call for an empirical treatment utilizing quarterly time series data.

\section{REFERENCES}

Alexiou, C. (2010) A Keynesian-Kaleckian model of investment determination: a panel data investigation. F. Post. Keynes. Econ., 32, 429-446.

BAHÇE, S. \& ERES, B. (2012) Components of differential profitability in classical/Marxian theory of competition. Alternative Theories of Competition: Challenges to Orthodoxy (J. Moudud, C. BINA \& P. MASON eds). London: Routledge.

BEAN, C. (1981) An econometric model of manufacturing investment in the UK. Econ. F. 91, 106-121.

Catinat, M., Cawley, R., Ilzkovitz, E., Italianer, A. \& Mors, M. (1987) The determinants of investment. Eur. Econ., 31, 5-60.

Chirinko, R. (1993) Business fixed investment spending: modeling strategies, empirical results, and policy implications. F. Econ. Lit., 31, 1875-1911. 
Ciccone, R. (1986) Accumulation and capacity utilisation: some critical considerations on Joan Robinson's theory of distribution. Polit. Econ., 2, 17-36.

Davidson, P. (1995) Uncertainty in economics, in Keynes, Knowledge and Uncertainty (S. Dow \& J. Hillard eds) Aldershot: Edward Elgar, pp. 107-116.

Eatwell, J. \& Millgate, M. (2011) The Fall and the Rise of Keynesian Economics, Oxford: Oxford University Press.

Eatwell, J., Milgate, M. \& Newman, P. (eds) (1993) The New Palgrave Capital Theory, London: Macmillan.

Elton, E., Gruber, M., Brown, S. \& Goetzmann, W. (2003) Modern Portfolio Theory and Investment Analysis, Hoboken, NJ: John Willey \& Sons.

ENGLE, R. \& GRANGER, C. (1987). Cointegration and error correction: representation, estimation, and testing. Econometrica, 55, 251-276.

Garegnani, P. (1978-1979). Notes on consumption, investment and effective demand, I \& II. Cambridge f. Econ., 2, 335-353; 3, 63-82.

HADRI, K. (2000) Testing for stationarity in heterogeneous panel data. Econom. F. 3, 148-161.

Harris, R. (1995) Using Cointegration Analysis in Econometric Modelling, Essex : Prentice Hall Publishing.

IM, K.S., Pesaran, M.H. \& ShIN, Y. (2003) Testing for unit roots in heterogeneous panels. $\mathcal{F}$. Econom., 115, 53-74.

Junankar, P.N. (1972) Investment: Theories and Evidence, London: Macmillan.

KALDOR, N. (1966) Causes of the Slow Rate of Economic Growth in the United Kingdom, Cambridge: Cambridge University Press; reprinted in N. Kaldor (ed.) (1978), Further Essays on Economic Theory, New York: Holmes \& Meier.

Kalecki, M. (1968) Theory of Economic Dynamics, New York: Monthly Review Press.

KeYnes, J.M. (1964 [1936]) The General Theory of Employment, Interest and Money, New York: Harcourt, Brace and World, Inc.

Keynes, J.M. (1971-1989) The Collected Writings of fohn Maynard Keynes (D.E. Moggridge ed.), vol. XIV, London: Macmillan.

KuRz, H. (1990) Technical change, growth and distribution: a steady-state approach to "unsteady" growth, in Capital, Distribution and Effective Demand (H.D. KuRZ ed.). Cambridge: Polity Press.

Kydland, F. \& PRESCOTt E. (1977) Rules rather than discretion: the inconsistency of optimal plans. F. Polit. Econ., 85, 473-492

Levin, A., Lin, C. \& ChU, C. (2002) Unit root tests in panel data: asymptotic and finite sample properties. F. Econom., 108, 1-24.

Mejorado, A. \& Roman, M. (2014) Profitability and the Great Recession: The Role of Accumulation Trends in the Financial Crisis, New York: Routledge.

Pagan, A. \& Wickens, M. (1989) A survey of some recent econometric methods. Econ. F. 99, 962-1025.

Pedroni, P. (1996) Fully modified OLS for heterogeneous cointegrated panels and the case of purchasing power parity. Indiana University Working Papers in Economics (No. 96-020)

Pedroni, P. (1999) Critical values for cointegration tests in heterogeneous panels with multiple regressors. Oxf. Bull. Econ. Stat., 61, 653-670.

Pedroni, P. (2000) Fully modified OLS for heterogeneous cointegrated panels. Adv. Econ., 15, 93-130

Pesaran, H. \& Smith, R. (1995) Estimating long-run relationships from dynamic heterogeneous panels. F. Econom., 68, 79-113.

Richardson, C. \& Romilly, P. (2008). Investment functions and the profitability gap. F. Post Keynes. Econ., 31, 35-56.

Robinson, J. (1962) Essays in the Theory of Economic Growth, London: Macmillan.

Sawyer, M. (1985) The Economics of Michal Kalecki, Armonk, NY: M.E. Sharpe. 
Scherer, F. \& Ross, D. (1990) Industrial Market Structure and Economic Performance. Boston, MA: Houghton Mifflin.

Semmler, W. \& Franke, R. (1995) The financial-real interaction and investment in the business cycle theory and empirical evidence, in Money in Motion (E. Nell \& G. Deleplace eds). London: MacMillan Press.

SHAIKH, A. (1997 [1995]) The stock market and the corporate sector: a profit-based approach, in Essays in Honour of Geoff Harcourt (P. Arestis, G. Palma \& M. SAwyer eds). London: Routledge.

Shaikh, A. (2016) Capitalism: Real Competition, Turbulent Dynamics, and Global Crises, Oxford: Oxford University Press.

Tsoulfidis, L. (2008) Keynes on the marginal efficiency of capital and the great depression. Hist. Econ. Ideas, 16, 65-78

Tsoulfidis, L. (2010) Competing Schools of Economic Thought, Dordrecht: Springer.

Tsoulfidis, L. \& Tsaliki, P. (2012) Classical competition and regulating capital: theory and empirical evidence, in Alternative Theories of Competition: Challenges to Orthodoxy (J. Moudud, C. Bina \& P. Mason eds). London: Routledge.

Tsoulfidis, L. \& Tsaliki, P. (2014) Unproductive labour, capital accumulation and profitability crisis in the Greek economy. Int. Rev. Appl. Econ., 28, 562-585.

VAONA, A. (2011) An empirical investigation into the gravitation and convergence of industry return rates in OECD countries. Int. Rev. Appl. Econ., 25, 465-502.

Vianello, F. (1985) The pace of accumulation. Polit. Econ., 1, 69-87.

doi:10.1093/cpe/bzw004 Advance Access Publication 0, 0000 